\title{
Mixotrophic cultivation of Chlorella vulgaris using industrial dairy waste as organic carbon source
}

\author{
Ana P. Abreu, Bruno Fernandes, António A. Vicente, José Teixeira, Giuliano Dragone* \\ IBB - Institute for Biotechnology and Bioengineering, Centre of Biological Engineering, University of Minho, Campus de Gualtar, 4710-057 Braga, Portugal
}

\section{H I G H L I G H T S}

- Cheese whey was used as carbon source for Chlorella vulgaris growth.

- Mixotrophic microalgae grew faster than photoautotrophic cells.

- Maximum starch productivity was achieved under mixotrophic conditions.

- Highest pigment content $(0.74 \%)$ was obtained in the photoautotrophic culture.

\section{A R T I C L E I N F O}

\section{Article history:}

Received 19 February 2012

Received in revised form 12 May 2012

Accepted 14 May 2012

Available online 23 May 2012

\section{Keywords:}

Biofuels

Cheese whey

Chlorella vulgaris

Microalgae

Mixotrophic

\begin{abstract}
A B S T R A C T
Growth parameters and biochemical composition of the green microalga Chlorella vulgaris cultivated under different mixotrophic conditions were determined and compared to those obtained from a photoautotrophic control culture. Mixotrophic microalgae showed higher specific growth rate, final biomass concentration and productivities of lipids, starch and proteins than microalgae cultivated under photoautotrophic conditions. Moreover, supplementation of the inorganic culture medium with hydrolyzed cheese whey powder solution led to a significant improvement in microalgal biomass production and carbohydrate utilization when compared with the culture enriched with a mixture of pure glucose and galactose, due to the presence of growth promoting nutrients in cheese whey. Mixotrophic cultivation of $C$. vulgaris using the main dairy industry by-product could be considered a feasible alternative to reduce the costs of microalgal biomass production, since it does not require the addition of expensive carbohydrates to the culture medium.
\end{abstract}

\section{Introduction}

Microalgae cultivation has been carried out throughout the world in order to produce animal feed or high-value added products, such as cosmetics, pharmaceuticals and health supplements (Das et al., 2011). More recently, microalgae have also been used for wastewater treatment, carbon dioxide $\left(\mathrm{CO}_{2}\right)$ mitigation, or as a feedstock for biofuel production (Brennan and Owende, 2010). These photosynthetic microorganisms can be cultivated either in open ponds or closed photobioreactors (PBR) using $\mathrm{CO}_{2}$ and light as carbon and energy sources, respectively (Chen et al., 2011). Nonetheless, this culture mode, known as photoautotrophic, presents several disadvantages including low cell densities and long cultivation periods. Hence, heterotrophic and mixotrophic growth regimes have been proposed as feasible alternatives for the production of microalgal biomass (Yu et al., 2009).

\footnotetext{
* Corresponding author. Tel.: +351 253604424; fax: +351 253604429 .

E-mail addresses: gdragone@deb.uminho.pt, giulianodragone@hotmail.com (G. Dragone).
}

Heterotrophic cultivation of microalgae involves the utilization of organic compounds as sole carbon source, while mixotrophic cultivation use simultaneously inorganic (for example $\mathrm{CO}_{2}$ ) and organic compounds as carbon source (Dragone et al., 2010). Therefore, microorganisms cultivated under mixotrophic conditions synthesize compounds characteristic of both photosynthetic and heterotrophic metabolisms at high production rates. Additionally, lower energy costs have been associated with mixotrophic cultivation in comparison with photoautotrophic cultures, due to its relatively lower requirements for light intensities (Cerón García et al., 2005).

Despite mixotrophic cultivation of microalgae provides higher biomass and lipid productivities than cultivation under photoautotrophic conditions, the cost of the organic carbon substrate is estimated to be about $80 \%$ of the total cost of the cultivation medium (Bhatnagar et al., 2011). As a result, less costly organic sources have to be found in order to overcome the high carbon cost resulting from mixotrophic culture conditions (Liang et al., 2009). Cost reduction of growth media preparation with minimal undesired effects is crucial for a potential commercial application (Abad and 
Turon, in press). In this context, crude glycerol from biodiesel production, acetate from anaerobic digestion, and carbohydrates from agricultural and industrial wastes offer great promise as inexpensive organic substrates for the cultivation of microalgae on mixotrophic mode (Bhatnagar et al., 2011; Heredia-Arroyo et al., 2011).

Cheese whey $(\mathrm{CW})$, the liquid by-product remaining from the cheese manufacturing process constitutes a serious environmental problem of dairy industries due to its high organic matter content (Dragone et al., 2009). Among the major components of whey, the disaccharide lactose, which on hydrolysis yields glucose and galactose, is greatly responsible for its high Biochemical Oxygen Demand $(\mathrm{BOD}=30000-50000 \mathrm{mg} / \mathrm{L})$ and Chemical Oxygen Demand $(\mathrm{COD}=60000-80000 \mathrm{mg} / \mathrm{L})$. In addition to this carbohydrate, CW also contains proteins, lipids, water-soluble vitamins and minerals (González Siso, 1996).

Exogenous sugars, such as glucose, galactose, mannose, fructose, sucrose and lactose have been commonly used for mixotrophic and heterotrophic cultivation of microalgae (Shi et al., 1999). However, these carbohydrates are transported and assimilated by microalgae with different efficiencies (Sun et al., 2008). A previous study revealed, for example, that some strains of Chlorella successfully utilize glucose and galactose during growth at different light intensities (Dvoráková-Hladká, 1966). Furthermore, recent reports indicate that Chlorella vulgaris grown on glucose medium may provide microalgal biomass for biofuel production and biorefinery (Kong et al., in press).

The objective of this work was to study the mixotrophic growth of $C$. vulgaris, using a hydrolyzed CW solution as an alternative approach to photoautotrophic microalgal cultivation. To our knowledge, no similar study has been previously carried out using this dairy by-product for cultivation of $C$. vulgaris.

\section{Methods}

\subsection{Microalgal strain and inoculum preparation}

The freshwater microalga C. vulgaris (strain P12) was used in all experiments. The microalgal inoculum was prepared according to previous studies (Fernandes et al., 2010) and conducted at $30^{\circ} \mathrm{C}$ in 0.5 -L glass photobioreactors under photoautotrophic conditions. The culture was aerated with $\mathrm{CO}_{2}$-enriched air $\left(2 \% \mathrm{v} / \mathrm{v} \mathrm{CO} \mathrm{CO}_{2}\right)$ at $0.4 \mathrm{vvm}$, and illuminated with continuous light $\left(70 \mu \mathrm{mol} / \mathrm{m}^{2} \mathrm{~s}\right)$ as reported by Dragone et al. (2011a).

\subsection{Media and culture conditions}

Four different cultivation conditions were carried out in duplicate (Table 1). The organic carbon sources used for mixotrophic cell growth were: a non-hydrolyzed CW powder solution, a mixture of pure glucose and galactose, and a hydrolyzed CW powder solution.

Sweet CW powder was supplied by Lactogal (Porto, Portugal). Its composition included $(\mathrm{w} / \mathrm{w}$ ): $>73 \%$ lactose, $12 \%$ proteins, $1.5 \%$ lipids and $<5 \%$ moisture. Non-hydrolyzed CW powder solution (nhCW) was prepared with distilled water and deproteinised by heat treatment as described elsewhere (Dragone et al., 2011b). Initial lactose concentration in nhCW was about $10 \mathrm{~g} / \mathrm{L}$. Hydrolyzed $\mathrm{CW}$ solution (hCW) containing glucose and galactose was obtained by hydrolyzing nhCW with $\beta$-galactosidase ( $>8.0$ units $/ \mathrm{mg}$, SigmaAldrich) from Aspergillus oryzae. Enzymatic hydrolysis was performed at $30{ }^{\circ} \mathrm{C}$ and $\mathrm{pH} 4.5$ with $0.02 \%$ of enzyme during $24 \mathrm{~h}$. Glucose and galactose concentrations attained a maximum of $5 \mathrm{~g} / \mathrm{L}$ at the end of the reaction and no lactose was detected in hCW.

All the experimental assays were carried out at $30{ }^{\circ} \mathrm{C}$ in $0.5-\mathrm{L}$ glass photobioreactors containing $400 \mathrm{~mL}$ of medium, under a light intensity of approximately $70 \mu \mathrm{mol} / \mathrm{m}^{2} \mathrm{~s}$ measured by a LI-250
Table 1

Different cultivation conditions of $C$. vulgaris and respective carbon sources.

\begin{tabular}{ll}
\hline $\begin{array}{l}\text { Growth } \\
\text { condition }\end{array}$ & Carbon Source \\
\hline Photoautotrophic & $\mathrm{CO}_{2}$ \\
Mixotrophic & \\
Mixotrophicw & $\mathrm{CO}_{2}+$ Non-hydrolyzed $\mathrm{CW}$ solution $(10 \mathrm{~g} / \mathrm{L}$ lactose $)$ \\
& $\begin{array}{l}\mathrm{CO}_{2}+\text { Hydrolyzed CW solution }(5 \mathrm{~g} / \mathrm{L} \text { glucose }+5 \mathrm{~g} / \mathrm{L} \\
\text { galactose })\end{array}$ \\
Mixotrophic $_{\mathrm{G}+\mathrm{G}}$ & $\mathrm{CO}_{2}+$ Glucose $(5 \mathrm{~g} / \mathrm{L})+$ Galactose $(5 \mathrm{~g} / \mathrm{L})$ \\
\hline
\end{tabular}

Light Meter with a LI-190 quantum sensor (LI-COR, USA). Agitation during cell growth was provided by sparging $\mathrm{CO}_{2}$-enriched air $\left.(2 \% \mathrm{v} / \mathrm{v} \mathrm{CO})_{2}\right)$ from the base of the photobioreactors at $0.400 \mathrm{vvm}$. Initial cell concentration was about $0.5 \mathrm{~g} / \mathrm{L}$ for all the cultivation conditions.

After reaching the stationary growth phase, cells were collected and centrifuged at $8750 \times \mathrm{g}$ for $10 \mathrm{~min}$, washed with distilled water and then freeze-dried for further biochemical characterization. The supernatant was also collected and frozen for subsequent sugar analyses.

\subsection{Determination of microalgal cell concentration}

Cell concentration in the photobioreactor cultures was measured regularly by using an improved Neubauer hemocytometer. Biomass concentration was estimated by cell dry weight after centrifugation of the sample $(8750 \times \mathrm{g}$ for $10 \mathrm{~min})$, washing with distilled water and drying at $105^{\circ} \mathrm{C}$ until constant weight.

\subsection{Determination of carbohydrate concentration in culture media}

Glucose, galactose and lactose concentrations in culture media were determined by High-Performance Liquid Chromatography (HPLC) in a Jasco chromatograph equipped with a refractive index (RI) detector (Jasco 830-RI, Japan) and a $300 \times 6.5 \mathrm{~mm}$ Chrompack column (Chrompack, The Netherlands) at $60^{\circ} \mathrm{C}$, using $5 \mathrm{mM}$ sulfuric acid as the eluent at a flow rate of $0.5 \mathrm{~mL} / \mathrm{min}$ and a sample volume of $20 \mu \mathrm{L}$.

\subsection{Determination of microalgal starch}

The starch content of $C$. vulgaris was assayed by enzymatic hydrolysis of the microalgal starch to glucose with $\alpha$-amylase and amyloglucosidase, according to Fernandes et al. (in press).

\subsection{Measurement of lipid and protein contents in microalgae}

Total lipids were determined by the classic Folch chloroformbased lipid extraction protocol. The protein content of microalgae was quantified according to the method of Lowry.

\subsection{Measurement of chlorophylls and total carotenoids concentration}

Chlorophylls and carotenoids in C. vulgaris were extracted with methanol and spectrophotometrically determined as described by Dere et al. (1998). Total pigment content was obtained by summing chlorophylls and carotenoids contents.

\subsection{Determination of specific growth rate}

The specific growth rate $\left(\mu\right.$ day $\left.^{-1}\right)$ was calculated from the Eq. (1), where $N_{1}$ and $N_{2}$ were the concentration of cells at the beginning $\left(t_{1}\right)$ and at the end $\left(t_{2}\right)$ of the exponential growth phase, respectively. 
$\mu=\left(\ln \mathrm{N}_{2}-\ln \mathrm{N}_{1}\right) /\left(t_{2}-t_{1}\right)$

\subsection{Determination of productivity of biomass, starch, lipids and} proteins

Biomass productivity $\left(P_{\max }, \mathrm{g} / \mathrm{L} \mathrm{d}\right)$ during the culture period was calculated from the Eq. (2), where $X_{t}$ was the biomass concentration $(\mathrm{g} / \mathrm{L})$ at the end of the exponential growth phase $\left(t_{x}\right)$ and $X_{0}$ the initial biomass concentration $(\mathrm{g} / \mathrm{L})$ at $t_{0}$ (day):

$P_{\max }=\left(X_{t}-X_{0}\right) /\left(t_{x}-t_{0}\right)$

Productivity of starch, lipids and proteins at the end of cultivation were calculated from the Eq. (3), where $P_{\text {component }}$ was the productivity of starch, lipids or proteins, $P_{\max }$ was the biomass productivity and $F_{\text {component }}$ was the mass fraction (w/w) of each component.

$P_{\text {component }}=P_{\max } \times F_{\text {component }}$

Data were compared using one-way ANOVA followed by a Tukey's multiple comparison tests with 95\% confidence level.

\section{Results and discussion}

\subsection{Growth parameters of microalgae cultivated under photoautotrophic and mixotrophic conditions}

Specific growth rate, final biomass concentration and biomass productivity of $C$. vulgaris cultivated under photoautotrophic and mixotrophic conditions were compared and summarized in Table 2. The highest specific growth rates of $C$. vulgaris were 0.43 and 0.47 day $^{-1}$ when microalgae were cultivated under mixotrophic conditions using hydrolyzed CW powder solution, and a mixture of glucose and galactose as organic carbon sources, respectively. These values were almost 3.5 times higher than those obtained when cells were grown in inorganic medium supplemented with non-hydrolyzed CW powder solution, and under photoautotrophic mode of nutrition.

Biomass concentration at the end of cultivation and biomass productivity were also significantly influenced by the nutritional conditions. It can be observed in Table 2 that the highest values of $X_{\max }(3.58 \mathrm{~g} / \mathrm{L})$ and $P_{\max }(0.75 \mathrm{~g} / \mathrm{L} \mathrm{d})$ achieved in the mixotrophic culture using hydrolyzed CW powder solution resulted in 2.9- and 7.5-fold increase respectively, when compared to the values obtained in the photoautotrophic culture. These results are in agreement with a previous study, which reported that mixotrophic $C$. vulgaris growth in glucose yielded higher biomass content and productivity than cells grown under photoautotrophic conditions (Kong et al., 2011). Mixotrophic cell cultivation utilizing both light and organic carbon source has been considered the most efficient

Table 2

Growth parameters of $C$. vulgaris cultivated under photoautotrophic and mixotrophic conditions at $30^{\circ} \mathrm{C}$

\begin{tabular}{llll}
\hline Growth condition & \multicolumn{3}{l}{ Growth parameters } \\
\cline { 2 - 4 } & $\mu_{\max }{ }^{*}\left(\right.$ day $\left.^{-1}\right)$ & $\mathrm{X}_{\max }{ }^{* *}(\mathrm{~g} / \mathrm{L})$ & $\mathrm{P}_{\max }{ }^{* * *}(\mathrm{~g} / \mathrm{L} \mathrm{d})$ \\
\hline Photoautotrophic & $0.13 \pm 0.01 \mathrm{a}$ & $1.22 \pm 0.12 \mathrm{a}$ & $0.10 \pm 0.01 \mathrm{a}$ \\
Mixotrophic $_{\mathrm{nhcw}}$ & $0.12 \pm 0.00 \mathrm{a}$ & $1.98 \pm 0.43 \mathrm{~b}$ & $0.32 \pm 0.13 \mathrm{ab}$ \\
Mixotrophic $_{\mathrm{hcw}}$ & $0.43 \pm 0.00 \mathrm{~b}$ & $3.58 \pm 0.12 \mathrm{c}$ & $0.75 \pm 0.01 \mathrm{c}$ \\
Mixotrophic $_{\mathrm{G}+\mathrm{G}}$ & $0.47 \pm 0.05 \mathrm{~b}$ & $2.24 \pm 0.34 \mathrm{~b}$ & $0.46 \pm 0.09 \mathrm{bc}$
\end{tabular}

Data are expressed as mean \pm standard error.

Means in the same column followed by different letters represent significant differences $(p<0.05)$

${ }^{*} \mu_{\max }=$ Specific growth rate during exponential growth phase

$X_{\max }^{* *}=$ Biomass concentration at the end of cultivation.

${ }^{* *} P_{\max }=$ Biomass productivity during the culture period. process for the production of microalgal biomass (Lee et al., 1996). When the light energy used for $\mathrm{CO}_{2}$ fixation is decreased in mixotrophic cultures, most of the energy is used for carbon assimilation. Therefore, since the amount of energy dissipated is minimal, mixotrophy provides higher energetic efficiency than other cultivation modes (Lalucat et al., 1984). On the other hand, Shi et al. (1999) reported that glucose can be considered the best organic C-substrate for the growth of Chlorella.

It is worth mentioning that the organic substrate played an important role in promoting biomass accumulation of $C$. vulgaris during microalgae cultivation. As shown in Table 2, supplementation of the inorganic culture medium with hydrolyzed CW powder solution led to higher biomass concentration than supplementation with a mixture of glucose and galactose. The stimulatory effect of hydrolyzed CW powder solution on biomass production is probably related to the presence of some nutrients in CW powder composition, such as phosphorous and calcium. Ozmihci and Kargi (2007) reported that CW powder contains approximately $0.96 \%$ total phosphorous on dry weight basis. Phosphorous is a macronutrient that plays a vital function in cellular metabolic processes by forming many structural and functional components required for normal growth and development of microalgae (Richmond, 2004).

It should be stated that the mineral content in whey depends upon the processing techniques used for casein removal from liquid milk. Consequently, a higher microalgal biomass concentration than that found in our study could have been obtained by using acid CW powder due to the higher concentrations of calcium and phosphorous presented in that type of whey (Mavropoulou and Kosikowski, 1973).

The presence of nutrients might have also supported $C$. vulgaris growth when using non-hydrolyzed $\mathrm{CW}$ powder solution, which showed a specific growth rate similar to the photoautotrophic control but with a higher final biomass concentration (Table 2 ).

Due to the high content of nutrients, other valorization pathways for CW have recently been proposed. Viitanen et al. (2003) showed that CW can be applied as an alternative inducer in recombinant high-cell density fermentations. According to these authors, $\mathrm{CW}$ can be directly used without any pretreatment, not causing a dilution of the fermentation medium.

Therefore, a potential application of hCW could be related with its use as a fermentation additive for microbial cultivation.

\subsection{Consumption of glucose and galactose by C. vulgaris}

The above presented results demonstrated that the microalgal species used in this study was able to grow mixotrophically in the presence of glucose and galactose. Therefore, consumption of both carbohydrates by $C$. vulgaris cultivated under mixotrophic conditions is shown in Table 3.

It was found that glucose and galactose were consumed in larger quantities during microalgal growth in the presence of the hydrolyzed CW powder solution, in comparison to the culture supplemented with a mixture of pure sugars. In particular, glucose was completely consumed and only $4 \%$ of the initial galactose concentration remained in the growth medium at the end of cultivation when hydrolyzed CW powder solution was used as carbon source. On the other hand, after nearly $90 \mathrm{~h}$ of cultivation, initial contents of glucose and galactose dropped $80.5 \%$ and $49.5 \%$, respectively, in the culture supplemented with both sugars. As discussed above, additional inorganic elements provided by hydrolyzed CW might have been responsible for the increased consumption of glucose and galactose derived from $\mathrm{CW}$ by $C$. vulgaris. These observations are in good agreement with a previous study where it was demonstrated that some components of hydrolyzed cheese whey enhanced carbohydrate utilization by microalgae (e.g. Euglena gracilis) (Freyssinet and Nigon, 1980). 
Table 3

Consumption of glucose and galactose by $C$. vulgaris cultivated under mixotrophic conditions at $30^{\circ} \mathrm{C}$.

\begin{tabular}{lll}
\hline Growth condition & \multicolumn{2}{l}{ Carbohydrate consumption (\%) } \\
\cline { 2 - 3 } & Glucose & Galactose \\
\hline Mixotrophic $_{\mathrm{nhCw}}$ & - & - \\
Mixotrophic $_{\mathrm{hcw}}$ & 100.0 & 96.0 \\
Mixotrophic $_{\mathrm{G}+\mathrm{G}}$ & 80.5 & 49.5 \\
\hline
\end{tabular}

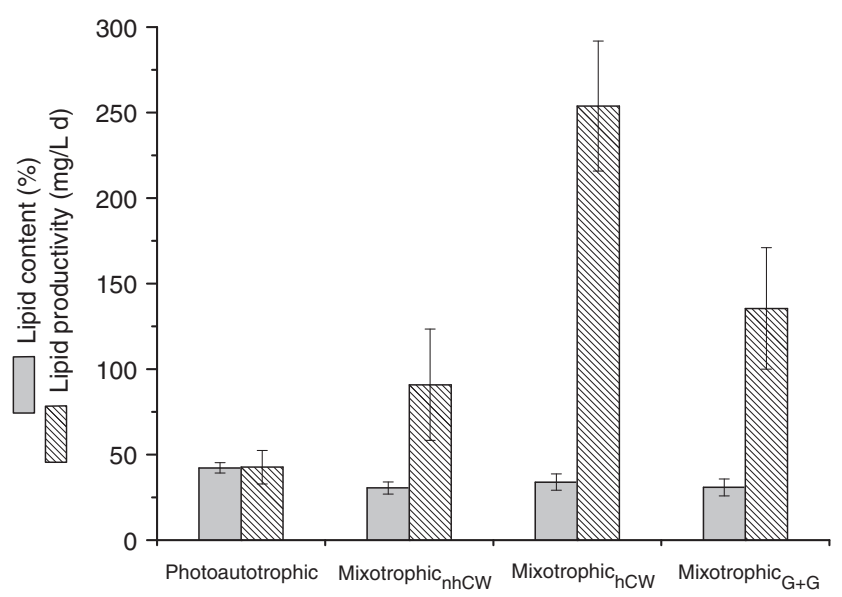

Fig. 1. Lipid content and lipid productivity of $C$. vulgaris under different nutritional conditions.

Regardless of the media used, glucose was more efficiently assimilated than galactose by $C$. vulgaris cells grown under mixotrophic conditions. Higher consumption of glucose compared to galactose for mixotrophic $C$. pyrenoidosa cultures was already described by Rodríguez-López (1966). A greater contribution to maintenance metabolism could explain the lesser assimilation of galactose when compared to glucose (Samejima and Myers, 1958).

\subsection{Influence of nutritional modes on biochemical composition of $C$. vulgaris}

The lipid content and lipid productivity of $C$. vulgaris under different growth conditions were compared and depicted in Fig. 1. When compared with mixotrophic cultures, higher lipid content (42\%) was obtained in photoautotrophic mode at the beginning of the stationary growth phase (approximately $190 \mathrm{~h}$ ). Other authors (Liang et al., 2009) have also shown that the amount of lipids accumulated in $C$. vulgaris under photoautotrophic growth conditions may surpass that from mixotrophic growth. On the other hand, the highest lipid productivity $(253 \mathrm{mg} / \mathrm{L} \mathrm{d}$ ) was achieved when cells were grown in culture medium supplemented with hydrolyzed CW powder solution, due to the highest growth rate and cell density. Mixotrophic microalgal cultivation with hCW yielded six times higher lipid productivity than photoautotrophic culture $(42 \mathrm{mg} / \mathrm{L} \mathrm{d})$. These results were remarkable in comparison with values presented in previous studies (Liang et al., 2009).

Different nutritional conditions had also different effects on starch content and starch productivity of C. vulgaris (Fig. 2). Although microalgal cells cultured photoautotrophically yielded the highest value of starch content (5.1\%), maximum starch productivities were achieved mixotrophically using a mixture of pure glucose and galactose, and a hydrolyzed CW powder solution, as a consequence of the highest biomass productivity obtained under mixotrophic conditions. The lower content of nutrients in the medium containing pure carbohydrates as compared to that in hydrolyzed CW medium, promoted lower biomass growth and sugar

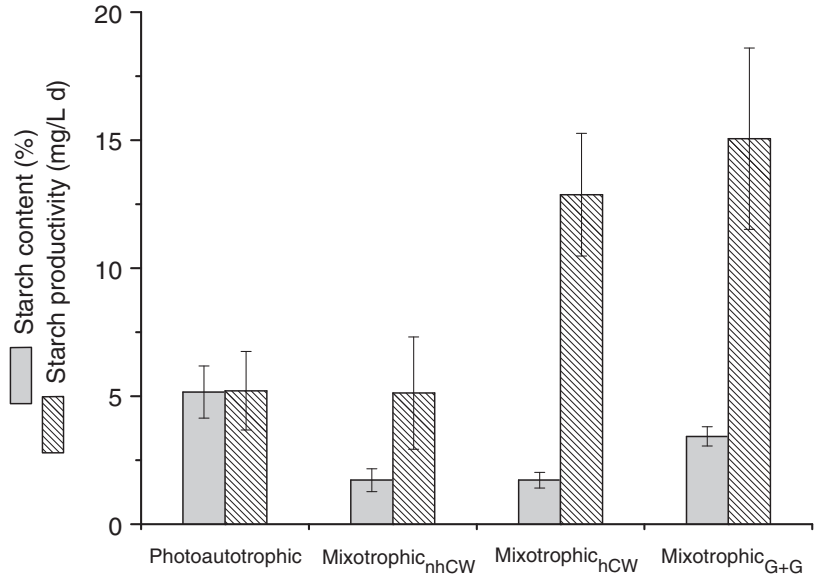

Fig. 2. Comparison of starch content and starch productivity of $C$. vulgaris grown under photoautotrophic and mixotrophic conditions.

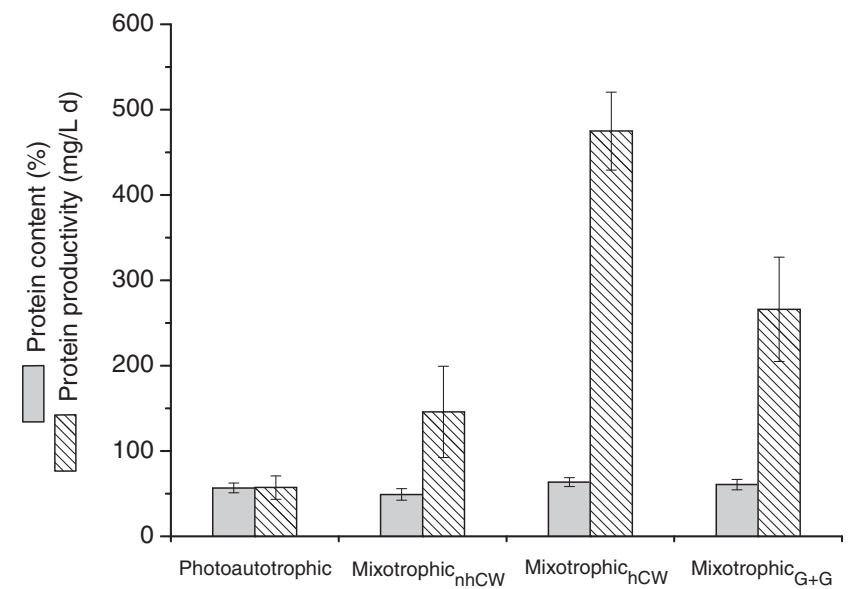

Fig. 3. Effect of nutritional mode on protein content and protein productivity of $C$. vulgaris.

consumption, and as a consequence of this stress condition, microalgal cells accumulated higher levels of starch. We have previously demonstrated (Dragone et al., 2011a) that higher starch accumulation in C. vulgaris P12 can be obtained under stressful growth conditions (e.g. by nutrient limitation). Therefore, since the starch productivity was calculated by multiplying the biomass productivity by the starch content $(\mathrm{w} / \mathrm{w})$ in microalgae, no differences on the values of this parameter were observed for the cells cultivated under mixotrophic conditions using hydrolyzed CW powder solution, and a mixture of glucose and galactose as organic carbon sources.

The protein content and protein productivity of photoautotrophic and mixotrophic microalgal cells were compared in Fig. 3. Cultivation of $C$. vulgaris $\mathrm{P} 12$ using hydrolyzed $\mathrm{CW}$ powder solution as organic carbon source led to the highest protein content (63.5\%) and protein productivity $(474 \mathrm{mg} / \mathrm{L} \mathrm{d})$. The highest protein content obtained in our study was significantly higher than that $(26 \%)$ found in C. vulgaris (strain 31 \#) cultivated in optimized mixotrophic medium with pure glucose as carbon source (Kong et al., in press).

The amount of total pigments in C. vulgaris cultured under photoautotrophic and mixotrophic conditions was also determined. As summarized in Table 4 , the maximum pigment content $(0.74 \%)$ was obtained in the photoautotrophic culture.

It has been suggested that the formation of photosynthetic apparatus in Chlorella may be disturbed by the presence of organic substrates (Yang et al., 2000), resulting in a decreased production 
Table 4

Total pigment (chlorophylls + carotenoids) content of $C$. vulgaris cultivated under photoautotrophic and mixotrophic conditions at $30^{\circ} \mathrm{C}$

\begin{tabular}{llll}
\hline \multirow{2}{*}{ Growth condition } & \multicolumn{3}{l}{ Pigment content $(\%)$} \\
\cline { 2 - 4 } & Chlorophylls $(\mathrm{a}+\mathrm{b})$ & Carotenoids & Total pigments \\
\hline Photoautotrophic & $0.51 \pm 0.09 \mathrm{c}$ & $0.23 \pm 0.04 \mathrm{~b}$ & $0.74 \pm 0.09 \mathrm{c}$ \\
Mixotrophic $_{\mathrm{nhcw}}$ & $0.60 \pm 0.17 \mathrm{c}$ & $0.09 \pm 0.03 \mathrm{a}$ & $0.69 \pm 0.17 \mathrm{c}$ \\
Mixotrophic $_{\mathrm{hcw}}$ & $0.22 \pm 0.07 \mathrm{a}$ & $0.04 \pm 0.02 \mathrm{a}$ & $0.26 \pm 0.07 \mathrm{a}$ \\
Mixotrophic $_{\mathrm{G}+\mathrm{G}}$ & $0.37 \pm 0.05 \mathrm{~b}$ & $0.08 \pm 0.02 \mathrm{a}$ & $0.46 \pm 0.05 \mathrm{~b}$ \\
\hline
\end{tabular}

Data are expressed as mean \pm standard error.

Means in the same column followed by different letters represent significant differences $(p<0.05)$.

of photosynthetic pigments when compared with that obtained in photoautotrophic mode. The higher content of chlorophylls obtained in the photoautotrophic culture when compared to mixotrophic cultures confirms such observation. The enhancement of chlorophyll biosynthesis by photoautotrophic Chlorella strains compared with that resulting from mixotrophic cells have been previously reported by several authors (Ip et al., 2004; Kong et al., 2011). On the other hand, Yan et al. (in press) reported that low chlorophyll content in mixotrophic cells decreases the dependence on light. Therefore, reduced amount of chlorophylls in microalgae may relieve photoinhibition.

Among the different nutritional modes tested, the highest carotenoids content $(0.23 \%)$ was also found in the photoautotrophic culture. This value dropped to $0.04 \%$ and $0.08 \%$ when cells were grown in inorganic medium supplemented with hydrolyzed $\mathrm{CW}$ powder solution, and with a mixture of pure glucose and galactose, respectively. These results are consistent with those of Liu et al. (2009) who found lower amount of carotenoids in mixotrophic cells when compared to cells grown on photoautotrophic culture.

\section{Conclusions}

When compared with the photoautotrophic control culture, mixotrophic microalgae grew faster, providing higher productivities of biomass, lipids, starch and proteins. Furthermore, microalgal biomass production and carbohydrate consumption were enhanced by supplementing the inorganic culture medium with hydrolyzed CW powder solution, than supplementing with a mixture of pure glucose and galactose, as a consequence of stimulatory effects arising from growth-promoting nutrients in CW. Mixotrophic cultivation of $C$. vulgaris using CW can be considered as a feasible strategy to reduce the costs of microalgal biomass production, while also contributing to solve the environmental problem caused by CW disposal in dairy industries.

\section{Acknowledgements}

This study was supported by the grants SFRH/BD/44724/2008 (Bruno Fernandes) and SFRH/BPD/44935/2008 (Giuliano Dragone) from Fundação para a Ciência e a Tecnologia (Portugal). The authors also acknowledge the financial support received through the projects INNOVALGAE (FCT PTDC/AAC-AMB/108511/2008) and ALGANOL.

\section{Appendix A. Supplementary data}

Supplementary data associated with this article can be found, in the online version, at http://dx.doi.org/10.1016/j.biortech.2012. 05.055 .

\section{References}

Abad, S., Turon, X., in press. Valorization of biodiesel derived glycerol as a carbon source to obtain added-value metabolites: focus on polyunsaturated fatty acids. Biotechnol. Adv.

Bhatnagar, A. Chinnasamy, S., Singh, M., Das, K.C., 2011. Renewable biomass production by mixotrophic algae in the presence of various carbon sources and wastewaters. Appl. Energy 88 (10), 3425-3431.

Brennan, L., Owende, P., 2010. Biofuels from microalgae - a review of technologies for production, processing, and extractions of biofuels and co-products. Renewable Sustainable Energy Rev. 14 (2), 557-577.

Cerón García, M.C., Sánchez Mirón, A., Fernández Sevilla, J.M., Molina Grima, E., García Camacho, F., 2005. Mixotrophic growth of the microalga Phaeodactylum tricornutum: influence of different nitrogen and organic carbon sources on productivity and biomass composition. Process Biochem. 40 (1), 297-305.

Chen, C.-Y., Yeh, K.-L., Aisyah, R., Lee, D.-J., Chang, J.-S., 2011. Cultivation, photobioreactor design and harvesting of microalgae for biodiesel production: a critical review. Bioresour. Technol. 102 (1), 71-81.

Das, P., Aziz, S.S., Obbard, J.P., 2011. Two phase microalgae growth in the open system for enhanced lipid productivity. Renewable Energy 36 (9), 2524-2528.

Dere, S.., Güneş, T., Sivaci, R., 1998. Spectrophotometric determination of chlorophyll - a, b and total carotenoid contents of some algae species using different solvents. Turk. J. Bot. 22 (1), 13-18.

Dragone, G., Mussatto, S.I., Oliveira, J.M., Teixeira, J.A., 2009. Characterisation of volatile compounds in an alcoholic beverage produced by whey fermentation. Food Chem. 112 (4), 929-935.

Dragone, G., Fernandes, B., Vicente, A., Teixeira, J.A., 2010. Third generation biofuels from microalgae. In: Vilas, A.M. (Ed.), Current Research, Technology and Education Topics in Applied Microbiology and Microbial Biotechnology, vol. 2. Formatex Research Center, Badajoz, pp. 1355-1366.

Dragone, G., Fernandes, B.D., Abreu, A.P., Vicente, A.A., Teixeira, J.A., 2011a. Nutrient limitation as a strategy for increasing starch accumulation in microalgae. Appl. Energy 88 (10), 3331-3335.

Dragone, G., Mussatto, S.I., Almeida e Silva, J.B., Teixeira, J.A., 2011b. Optimal fermentation conditions for maximizing the ethanol production by Kluyveromyces fragilis from cheese whey powder. Biomass Bioenergy 35 (5), 1977-1982.

Dvořáková-Hladká, J., 1966. Utilization of organic substrates during mixotrophic and heterotrophic cultivation of algae. Biol. Plant. 8 (5), 354-361.

Fernandes, B., Dragone, G., Teixeira, J., Vicente, A., 2010. Light regime characterization in an airlift photobioreactor for production of microalgae with high starch content. Appl. Biochem. Biotechnol. 161 (1), 218-226.

Fernandes, B., Dragone, G., Abreu, A., Geada, P., Teixeira, J., Vicente, A., in press. Starch determination in Chlorella vulgaris - a comparison between acid and enzymatic methods. J. Appl. Phycol., 1-6.

Freyssinet, G., Nigon, V., 1980. Growth of Euglena gracilis on whey. Appl. Microbiol. Biotechnol. 9 (4), 295-303.

González Siso, M.I., 1996. The biotechnological utilization of cheese whey: a review. Bioresour. Technol. 57 (1), 1-11.

Heredia-Arroyo, T., Wei, W., Ruan, R., Hu, B., 2011. Mixotrophic cultivation of Chlorella vulgaris and its potential application for the oil accumulation from non-sugar materials. Biomass Bioenergy 35 (5), 2245-2253.

Ip, P.-F., Wong, K.-H., Chen, F., 2004. Enhanced production of astaxanthin by the green microalga Chlorella zofingiensis in mixotrophic culture. Process Biochem. 39 (11), 1761-1766.

Kong, W., Song, H., Cao, Y., Yang, H., Hua, S., Xia, C., 2011. The characteristics of biomass production, lipid accumulation and chlorophyll biosynthesis of Chlorella vulgaris under mixotrophic cultivation. Afr. J. Biotechnol. 10 (55), $11620-11630$

Kong, W.-B., Hua, S.-F., Cao, H., Mu, Y.-W., Yang, H., Song, H., Xia, C.-G., in press. Optimization of mixotrophic medium components for biomass production and biochemical composition biosynthesis by Chlorella vulgaris using response surface methodology. J. Taiwan Inst. Chem. Eng.

Lalucat, J., Imperial, J., Parés, R., 1984. Utilization of light for the assimilation of organic matter in Chlorella sp. VJ79. Biotechnol. Bioeng. 26 (7), 677-681.

Lee, Y.-K., Ding, S.-Y., Hoe, C.-H., Low, C.-S., 1996. Mixotrophic growth of Chlorella sorokiniana in outdoor enclosed photobioreactor. J. Appl. Phycol. 8 (2), 163-169.

Liang, Y., Sarkany, N., Cui, Y., 2009. Biomass and lipid productivities of Chlorella vulgaris under autotrophic, heterotrophic and mixotrophic growth conditions. Biotechnol. Lett. 31 (7), 1043-1049.

Liu, X., Duan, S., Li, A., Xu, N., Cai, Z., Hu, Z., 2009. Effects of organic carbon sources on growth, photosynthesis, and respiration of Phaeodactylum tricornutum. J. Appl. Phycol. 21 (2), 239-246.

Mavropoulou, I.P., Kosikowski, F.V., 1973. Composition, solubility, and stability of whey powders. J. Dairy Sci. 56 (9), 1128-1134

Ozmihci, S., Kargi, F., 2007. Kinetics of batch ethanol fermentation of cheese-whey powder (CWP) solution as function of substrate and yeast concentrations. Bioresour. Technol. 98 (16), 2978-2984.

Richmond, A., 2004. Handbook of microalgal culture: biotechnology and applied phycology, first ed. Blackwell Science, Oxford.

Rodríguez-López, M., 1966. Utilization of sugars by Chlorella under various conditions. J. Gen. Microbiol. 43 (1), 139-143.

Samejima, H., Myers, J., 1958. On the heterotrophic growth of Chlorella pyrenoidosa. J. Gen. Microbiol. 18, 107-117. 
Shi, X.-M., Liu, H.-J., Zhang, X.-W., Chen, F., 1999. Production of biomass and lutein by Chlorella protothecoides at various glucose concentrations in heterotrophic cultures. Process Biochem. 34 (4), 341-347.

Sun, N., Wang, Y., Li, Y.-T., Huang, J.-C., Chen, F., 2008. Sugar-based growth, astaxanthin accumulation and carotenogenic transcription of heterotrophic Chlorella zofingiensis (Chlorophyta). Process Biochem. 43 (11), 1288-1292.

Viitanen, M., Vasala, A., Neubauer, P., Alatossava, T., 2003. Cheese whey-induced high-cell-density production of recombinant proteins in Escherichia coli. Microb. Cell Fact. 2 (1), 1-10.
Yan, R., Zhu, D., Zhang, Z., Zeng, Q., Chu, J., in press. Carbon metabolism and energy conversion of Synechococcus sp. PCC 7942 under mixotrophic conditions: comparison with photoautotrophic condition. J. Appl. Phycol., 1-12.

Yang, C., Hua, Q., Shimizu, K., 2000. Energetics and carbon metabolism during growth of microalgal cells under photoautotrophic, mixotrophic and cyclic light-autotrophic/dark-heterotrophic conditions. Biochem. Eng. J. 6 (2), 87-102.

Yu, H., Jia, S., Dai, Y., 2009. Growth characteristics of the cyanobacterium Nostoc flagelliforme in photoautotrophic, mixotrophic and heterotrophic cultivation. J. Appl. Phycol. 21 (1), 127-133. 